\title{
Colorless and Transparent Polyimide Microporous Film with Excellent Physicochemical Property
}

\author{
Jong Won Kim ${ }^{1}$, Seon Ju Lee ${ }^{2}$, Moon Young Choi ${ }^{2}$ and Jin-Hae Chang ${ }^{1,3, *(\mathbb{D})}$ \\ 1 Department of Polymer Science and Engineering, Kumoh National Institute of Technology, \\ Gumi 39177, Korea; kiw010@naver.com \\ 2 Graduate School of Carbon Convergence Engineering, Jeonju University, Jeonju 55069, Korea; \\ qaz5515@naver.com (S.J.L.); ansdud2303@naver.com (M.Y.C.) \\ 3 Institute of Carbon Technology, Jeonju University, Jeonju 55069, Korea \\ * Correspondence: changjinhae@hanmail.net
}

check for updates

Citation: Kim, J.W.; Lee, S.J.; Choi, M.Y.; Chang, J.-H. Colorless and Transparent Polyimide Microporous Film with Excellent Physicochemical Property. Polymers 2021, 13, 1298. https://doi.org/10.3390/polym 13081298

Academic Editor: Hui-Hsin Tseng

Received: 15 March 2021

Accepted: 13 April 2021

Published: 15 April 2021

Publisher's Note: MDPI stays neutral with regard to jurisdictional claims in published maps and institutional affiliations.

Copyright: (c) 2021 by the authors. Licensee MDPI, Basel, Switzerland. This article is an open access article distributed under the terms and conditions of the Creative Commons Attribution (CC BY) license (https:/ / creativecommons.org/licenses/by/ $4.0 /)$.

\begin{abstract}
BPADA) as a dianhydride and bis(3-aminophenyl) sulfone (APS) and bis(3-amino-4-hydroxyphenyl) sulfone (APS-OH) as diamines were used to synthesize two types of poly(amic acid) (PAA). Varying amounts (0-5.0 wt\%) of water-soluble poly(vinyl alcohol) (PVA) were mixed with PAA, and the resulting blend was heat-treated at different stages to obtain the colorless and transparent polyimide (CPI) blend films. The synthesized blended film completely removed water-soluble PVA in water. The possibility as a porous membrane according to the pore size varied according to the amount of PVA was investigated. The dispersibility and compatibility of CPI containing APS-OH monomer were higher than those of the APS monomer. This could be attributed to the hydrogen-bonding interactions between the CPI main chains and PVA. Scanning electron microscopy was conducted to characterize the material. The results revealed that the pore size of the CPI blend film increased as the PVA concentration increased. It was confirmed that uniform pores of $\mu \mathrm{m}$-size were observed in CPI. The thermal stabilities, morphologies, optical properties, and solubilities of two CPIs obtained using APS and APS-OH monomers were investigated and their properties were compared with each other.
\end{abstract}

Keywords: colorless and transparent polyimide; poly(vinyl alcohol); blend; microporous film; physicochemical property

\section{Introduction}

Many impurities present in industrial wastewater and domestic drinking water are difficult to remove because of their diverse and complex structures. Methods of treating contaminated solvents and wastewater include the use of simple filters, agglomeration, powdering, biological drainage, and ozonation. In addition, activated carbon adsorption, photocatalytic, and electrochemical processes have been used. However, it is difficult to completely remove impurities using these methods. In addition, most of these methods are more contaminated by impurities generated during refining [1-3].

Various types of membrane filters, including microfiltration (MF), nanofiltration (NF), hollow fiber membrane filtration (UF), and reverse osmosis (RO), have been applied to wastewater refinement, industrial fluids, and dye treatment. This filtration process is designed to filter a wide variety of materials [4,5]. Depending on the pore size, MF, UF, NF, and RO can separate small particles, macromolecules, nanomaterials, and ionic compounds, respectively. Therefore, the main water purification technology, MF was used to eliminate bacteria and various suspended substances, while UF was used to exclude colloids and various viruses. NF was used to remove heavy metals and organic substances from solvents, and $\mathrm{RO}$ was applied mainly in desalination, water reprocessing facilities, and household water purifiers. This method has been widely used in various fields and reported in many studies $[6,7]$. 
MF was first commercialized in 1929 by Sartorius Werke GmbH in Göttingen, Germany, to reliably supply drinking water by analyzing bacteria in water samples from several German cities bombed during World War II [8]. However, the first patent on a microporous membrane was registered by Zsigmondy in 1922 [9]. MF is a membrane process driven by pressure on a microporous membrane, removing suspended colloids and particles in the size range $0.1-20 \mathrm{~mm}$. MF is generally operated at a relatively low pressure (50 psi/3.4 bar/0.35 MPa) to separate impurities, but with an uncontaminated membrane, it operates at very high permeation rates $\left(10^{-4}-10^{-2} \mathrm{~m} / \mathrm{s}\right)$. These operating conditions make MF different from RO and UF [8]. Meanwhile, the characterizations and applications of various MF membranes, manufactured for water purification, have been demonstrated. Zhong et al. [10] developed a ceramic MF membrane, containing zirconium dioxide $\left(\mathrm{ZrO}_{2}\right)$, with excellent water treatment properties. Previous MF membrane studies have shown that inorganic membranes are substances effective in removing contamination through pretreatment steps, such as agglomeration [11,12].

Polyimide (PI) can be easily processed into membranes with high chemical and physical stability. PI membranes can be used under various conditions due to the unique properties of PI and have excellent separation properties for gases and liquids. In addition, PI showed various potential as a microporous film with excellent chemical resistance, thermo-mechanical properties, and processability [13,14].

PI has a characteristic brown color that absorbs light in the visible region through the transition of numerous $\pi$ electrons present in the main chain to the adjacent chain, owing to the characteristics of the aromatic structure. To remove such a brown color, a colorless and transparent PI (CPI) can be formed by introducing a monomer with a curved structure into the main chain, or by using a fluorine- $\left(-\mathrm{F},-\mathrm{CF}_{3}\right)$ or sulfone-substituted $\left(-\mathrm{SO}_{2}-\right)$ monomer with high electronegativity. $\mathrm{CPI}$ has superior thermal stability, solubility, and optical transparency compared to conventional, colored PIs. In addition, CPI films have many potential applications in electro-optical devices, especially in semiconductor applications, including flexible display devices $[15,16]$.

Poly(vinyl alcohol) (PVA) is the most widely known water-soluble polymer, but it is not produced by the direct reaction of the corresponding monomer, which is spontaneously converted thermodynamically to the enol form of acetaldehyde. It is commercially produced through the hydrolysis of poly(vinyl acetate). PVA is widely used for flexible, water-soluble packaging films, coatings, and textile sizing [17]. PVA contributed to improving the thermo-mechanical properties of a blend film consisting of various polymers, while maintaining its optical transparency. Additionally, various polymeric materials containing PVA can be applied not only as blends but also as substitutes for other polymer materials in special fields with high functionality [18-20].

Compounds containing - $\mathrm{OH}$ allow strong intermolecular hydrogen bonding, an electrostatic attraction that occurs between atoms with high electronegativity, such as $\mathrm{O}, \mathrm{N}, \mathrm{F}$, and $\mathrm{H}$ atoms in neighboring molecules attached to a similar electronegative atom $(\mathrm{O}, \mathrm{N}$, or $\mathrm{F})$, and is a type of intermolecular attraction. In addition, hydrogen bonds are considered relatively strong among the typical intermolecular forces [21].

In our study, the main chain structure of $\mathrm{CPI}$ was designed to include an - $\mathrm{OH}$ group, and its properties were compared to those of the general CPI structure without the $\mathrm{OH}$ group. If hydrophilic CPI with -OH groups is blended with PVA to form hydrogen bonds, we expect the blends to exhibit excellent dispersibility and compatibility through hydrogen bonding.

The purpose of this study was to synthesize CPI blend films with various pore sizes. To this end, a poly(amic acid) (PAA)/PVA blend film was synthesized by blending PVA in the range $0-5 \mathrm{wt} \%$ with the synthesized PAA, and, after synthesizing a CPI/PVA blend film through various heat treatment processes, a CPI microporous film was prepared by removing the water-soluble PVA with an aqueous solution. In addition, this study investigated the potential of CPI for membrane fabrication by improving the thermal properties, optical transparencies, and chemical resistances. We also focused on controlling 
the $\mu \mathrm{m}$-size of the CPI membrane using a simple method of dissolving water-soluble PVA in water.

\section{Materials and Methods}

\subsection{Materials}

Bis(3-aminophenyl) sulfone (APS), bis(3-amino-4-hydroxyphenyl) sulfone (APS-OH), and $4,4^{\prime}-\left(4,4^{\prime}\right.$-isopropylidenediphenoxy)bis(phthalic anhydride) (BPADA) were purchased from Santa Cruz Biotechnology (Shanghai, China) and Tokyo Chemical Industry (Tokyo, Japan). $\mathrm{N}, \mathrm{N}$-dimethylacetamide (DMAc) was obtained from Junsei Chemical Co., Ltd. (Tokyo, Japan), and moisture was completely removed with molecular sieves (4 A). PVA obtained through an $80 \%$ degree of saponification $\left(\mathrm{DP}=2.04 \times 10^{2}\right)$ was obtained from Aldrich Chemical Co (Yongin, Korea). All other solvents were used without further purification.

\subsection{Methods}

The methods for synthesizing CPI using two monomers, APS and APS-OH, were identical. For example, the synthesis using APS proceeded as follows: PAA was obtained from BPADA and APS, using DMAc. BPADA $\left(6.92 \mathrm{~g} ; 1.3 \times 10^{-2} \mathrm{~mol}\right)$ and $40 \mathrm{~mL}$ of DMAc were mixed in a beaker at $0{ }^{\circ} \mathrm{C}$ for 30 min under $\mathrm{N}_{2}$ atmosphere. In a separate beaker, DMAc $(20 \mathrm{~mL})$ was mixed with APS $\left(3.30 \mathrm{~g} ; 1.3 \times 10^{-2} \mathrm{~mol}\right)$, and this solution was then mixed with the prepared BPADA solution.

For stabilization under $\mathrm{N}_{2}$ condition, the solution was slowly stirred at $25{ }^{\circ} \mathrm{C}$ for $1 \mathrm{~h}$, and then at $0{ }^{\circ} \mathrm{C}$ for $1 \mathrm{~h}$, and then at $25^{\circ} \mathrm{C}$ for $12 \mathrm{~h}$ to prepare a PAA solution. To a three-necked flask with a reflux condenser, PVA $\left(0.1 \mathrm{~g} ; 2.3 \times 10^{-2} \mathrm{~mol}\right), 1 \mathrm{wt} \%$ PAA solid content, was supplemented to the PAA, followed by mixing under $\mathrm{N}_{2}$ atmosphere at $50{ }^{\circ} \mathrm{C}$ for $3 \mathrm{~h}$. The PAA/PVA blend was coated on a glass panel to a certain thickness using a coating bar, and the solvent was slowly eliminated while stabilizing the PAA for $2 \mathrm{~h}$ at $50{ }^{\circ} \mathrm{C}$ in a vacuum oven. The solvent was then completely removed under vacuum at $80^{\circ} \mathrm{C}$ for $1 \mathrm{~h}$ to prepare blended PAA/PVA films. The thermal imidization reaction to obtain the CPI/PVA blend film was maintained at 110,140 , and $170{ }^{\circ} \mathrm{C}$ under vacuum for $30 \mathrm{~min}$, and then heat-treated at 195 and $220^{\circ} \mathrm{C}$ for $50 \mathrm{~min}$. After all, heat imidization was finished by holding the mixture at $235^{\circ} \mathrm{C}$ for $2 \mathrm{~h}$. The detailed reaction conditions are listed in Table 1. After completion of the imide reaction, the CPI/PVA film was slowly peeled off the glass panel in water at $90^{\circ} \mathrm{C}$. The overall synthetic route is illustrated in Scheme 1.

Table 1. Synthetic conditions of the CPI/poly(vinyl alcohol) (PVA) blend films containing different diamines.

\begin{tabular}{cc}
\hline Samples & Temperature $\left({ }^{\circ} \mathrm{C}\right) /$ Time $(\mathbf{h}) /$ Pressure (Torr) \\
\hline PAA & $25 / 1 / 760 \rightarrow 0 / 1 / 760 \rightarrow 25 / 12 / 760$ \\
PAA PVA blend & $50 / 3 / 760$ \\
CPI/PVA blend & $50 / 2 / 1 \rightarrow 80 / 1 / 1 \rightarrow 110 / 0.5 / 1 \rightarrow 140 / 0.5 / 1 \rightarrow$ \\
& $170 / 0.5 / 1 \rightarrow 195 / 0.8 / 1 \rightarrow 220 / 0.8 / 1 \rightarrow 235 / 2 / 1$ \\
\hline
\end{tabular}

\subsection{Synthesis of Microporous CPI Film}

Because PVA is a hydrophilic polymer, it is completely soluble in hot water. Therefore, when the CPI/PVA blend film was immersed in water at $90{ }^{\circ} \mathrm{C}$ for $5 \mathrm{~h}$ to completely dissolve the PVA component in the blend film, it was possible to prepare porous CPI membrane films with the desired pore sizes, according to various amounts of PVA (wt\%). 


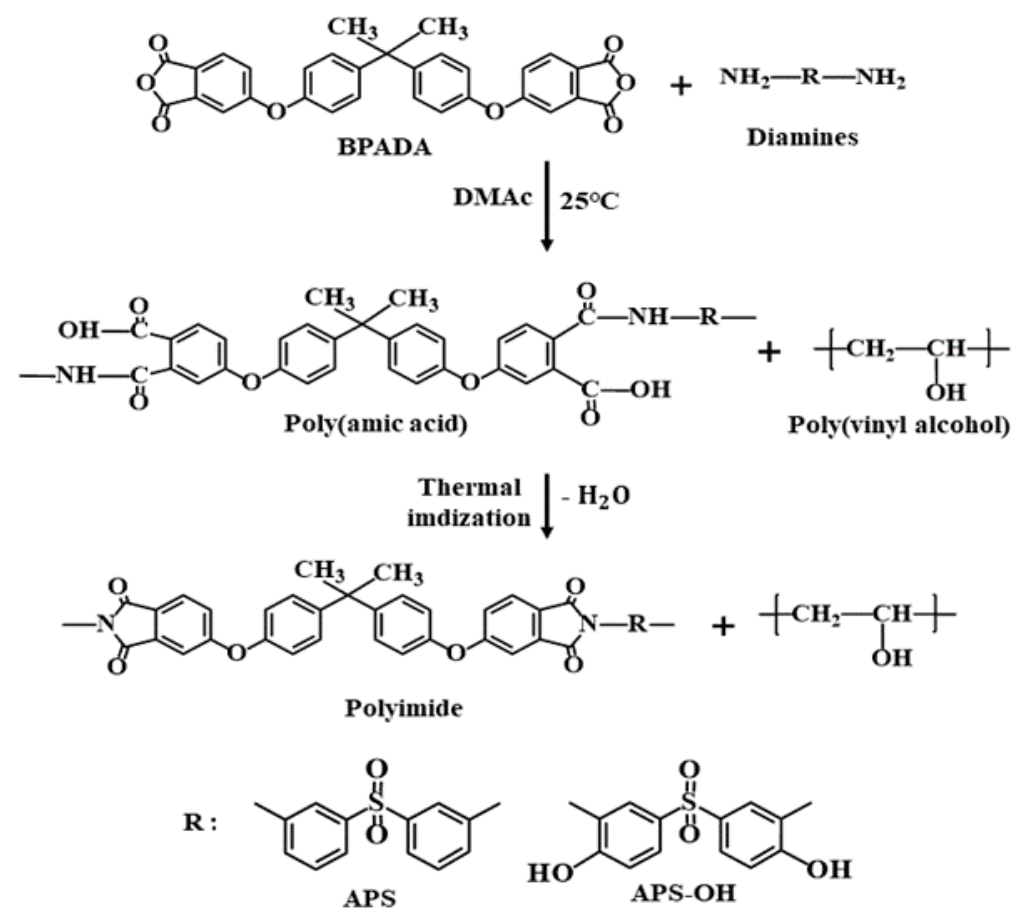

Scheme 1. Synthetic route of CPI blend films containing different diamines.

\subsection{Characterization}

The structure of the synthesized material was confirmed using Fourier-transform infrared (FT-IR) spectroscopy (Bruker VERTEX 80v, Berlin, Germany) and Carbon-13 nuclear magnetic resonance $\left({ }^{13} \mathrm{C}\right.$-NMR) spectroscopy (Bruker 400 DSX NMR, Berlin, Germany). The ${ }^{13} \mathrm{C}$ cross-polarization (CP)/magic-angle spinning (MAS) NMR experiment was conducted at a Larmor frequency of $100.61 \mathrm{MHz}$. To minimize the spinning sideband, it was measured at an MAS rate of $12 \mathrm{kHz}$. Tetramethylsilane (TMS) was used as a standard to record the NMR spectra.

The thermal properties were investigated by differential scanning calorimetry (DSC, NETZSCH 200F3, Berlin, Germany) and thermogravimetric analysis (TGA, TA Instruments TA Q500, New Castle, DE, USA) under $\mathrm{N}_{2}$ atmosphere. The rate of temperature increase was maintained at $20^{\circ} \mathrm{C} / \mathrm{min}$.

The degree of crystallinity (DC) of the film was measured with an X-ray diffractometer (XRD, Rigaku XRD, Tokyo, Japan) with $\mathrm{Cu} \mathrm{K} \alpha$ radiation. Measurements were carried out at a scan rate step size of $2^{\circ} / \mathrm{min}$ in the $2 \theta$ range $2^{\circ}-40^{\circ}$. The pore size of the films was investigated using a field emission scanning electron microscope (SEM, JEOL JSM-6500F, Tokyo, Japan). To investigate the optical transparencies, a spectrophotometer (Konica Minolta CM-3600D, Tokyo, Japan) and a UV-visible (UV-vis) spectrophotometer (Shimadzu UV-3600, Tokyo, Japan) were used.

\section{Results and Discussion}

\subsection{FT-IR}

The FT-IR spectra of the CPI films synthesized using APS or APS-OH monomers are shown in Figure 1. For the APS CPI film (Figure 1a), a $\mathrm{C}=\mathrm{O}$ aromatic stretching peak was observed at $1778 \mathrm{~cm}^{-1}$ and $1718 \mathrm{~cm}^{-1}$, and a $\mathrm{C}-\mathrm{N}-\mathrm{C}$ peak, representing an imide cyclization, was shown at $1360 \mathrm{~cm}^{-1}$. However, for the APS-OH CPI film (Figure 1b), a wide O-H stretching peak was shown at $\sim 3300 \mathrm{~cm}^{-1}$. Since the -OH groups present in CPI are capable of hydrogen bonding, the intensity of the -OH elongation peak appearing on the CPI film is lower than that of the commonly observed hydroxyl peak. Molecules with -OH functional groups are capable of intramolecular hydrogen bonding between CPI main chains and represent a broad elongation absorption peak through a wide wavenumber 
range (3000-3300 $\left.\mathrm{cm}^{-1}\right)$. Therefore, the APS-OH PI spectrum shows a broad peak due to hydrogen bonding between the nitrogen and the $-\mathrm{OH}$ group of phenol in the adjacent imide ring as shown in Figure 1 [22-24]. Similar to the APS CPI spectrum, the APS-OH CPI spectrum showed a $\mathrm{C}=\mathrm{O}$ aromatic stretching peak a $\mathrm{C}-\mathrm{N}-\mathrm{C}$ peak indicating imidization at $1777 \mathrm{~cm}^{-1}, 1716 \mathrm{~cm}^{-1}$, and $1380 \mathrm{~cm}^{-1}$, respectively. It was found that the two imide reactions were completed [25-27].

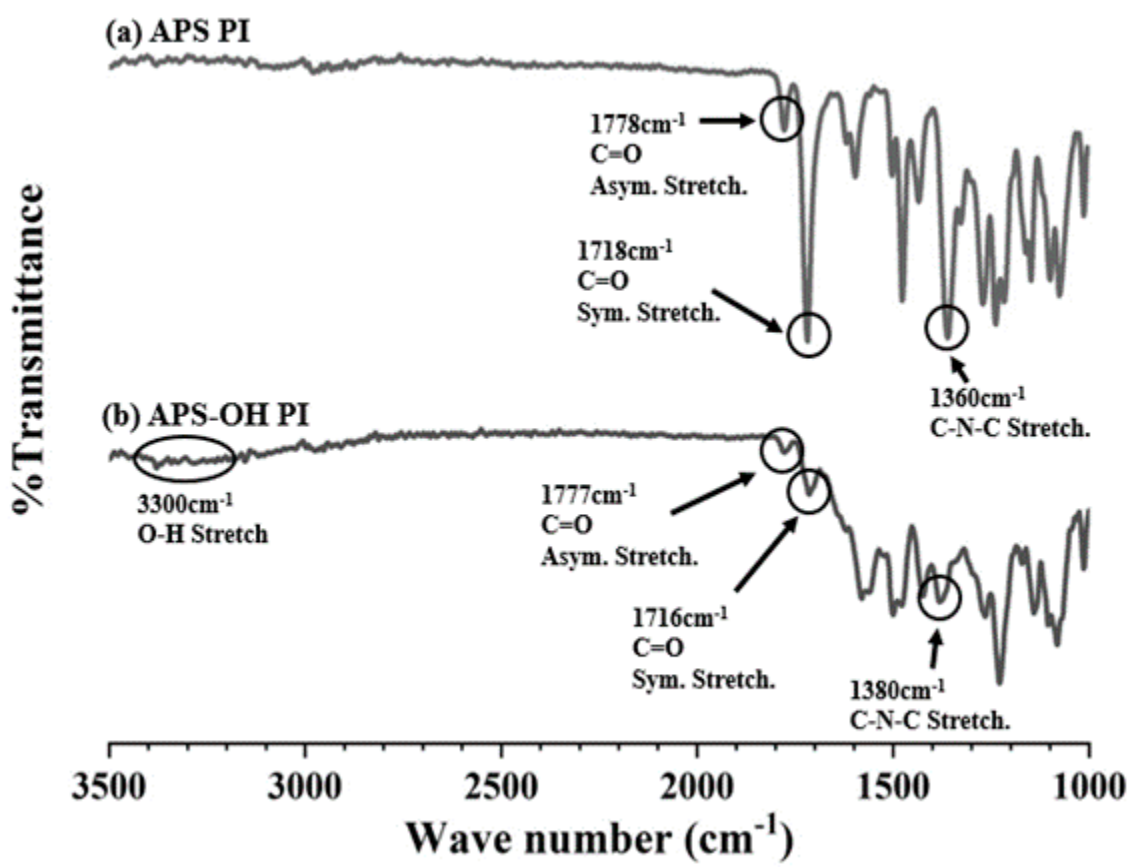

Figure 1. Fourier-transform infrared (FT-IR) spectra of CPI films containing (a) APS and (b) APS$\mathrm{OH}$ monomers.

\subsection{Solid State C-13 NMR}

The structural analyses of the synthesized APS CPI and APS-OH CPI was performed using solid-state ${ }^{13} \mathrm{C} C \mathrm{CP} / \mathrm{MAS}$ NMR, and the chemical shifts of ${ }^{13} \mathrm{C}$ at room temperature are shown in Figure 2a,b. The ${ }^{13} \mathrm{C}$ MAS NMR spectrum of TMS was obtained at $38.3 \mathrm{ppm}$ at $25^{\circ} \mathrm{C}$. This peak at $38.3 \mathrm{ppm}$ was taken as the standard and calibrated as a peak at $0 \mathrm{ppm}$. 
(a)

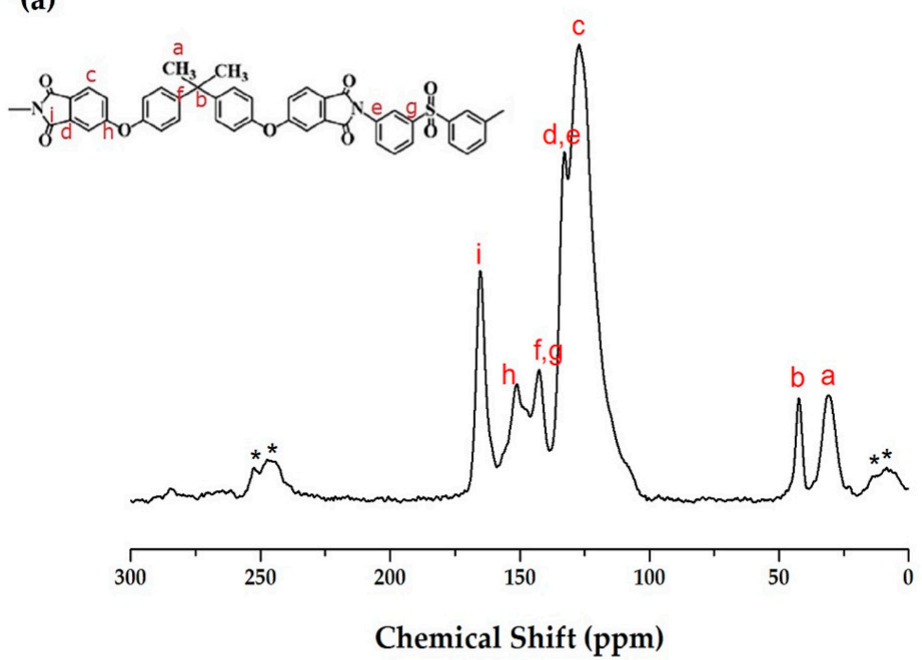

(b)

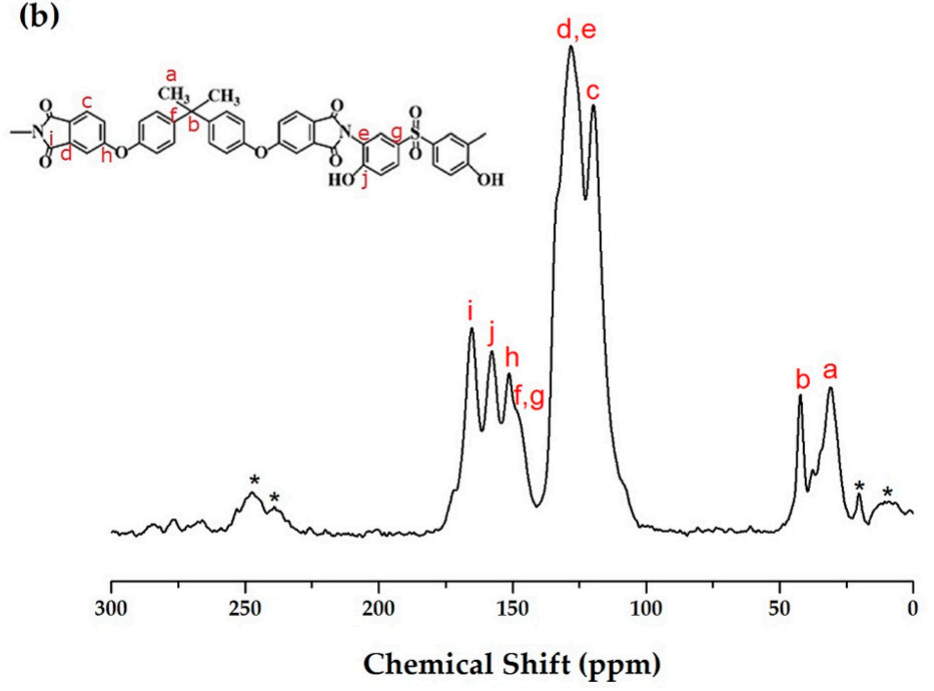

Figure 2. Carbon-13 nuclear magnetic resonance $\left({ }^{13} \mathrm{C}-\mathrm{NMR}\right)$ spectra of the CPI films containing (a) APS and (b) APS-OH monomers. The spinning sidebands are marked with asterisks.

In the APS CPI spectrum (Figure 2a), the chemical shifts for the methyl $\left(-\mathrm{CH}_{3}\right)$ and isopropyl carbons $\left(-\mathrm{C}-\left(\mathrm{CH}_{3}\right)_{2}\right)$ are observed at $30.96 \mathrm{ppm}$ and $42.42 \mathrm{ppm}$, respectively. The peaks at $127.25 \mathrm{ppm}, 133.01 \mathrm{ppm}, 142.67 \mathrm{ppm}$, and $151.25 \mathrm{ppm}$ are assigned to the phenyl carbons, and the chemical shift for the carbonyl carbon $(-\mathrm{C}=\mathrm{O})$ is observed at $165.26 \mathrm{ppm}$. The spinning sidebands for the phenyl carbons are marked with asterisks $\left(^{*}\right)$ in Figure 2.

In the APS-OH CPI spectrum (Figure $2 b$ ), the ${ }^{13} \mathrm{C}$ chemical shifts for the methyl, isopropyl, phenyl, and carbonyl carbons are similar to those observed in the APS CPI spectrum. In addition, the chemical shift for the OH-bonded carbon is observed at $157.71 \mathrm{ppm}$. The chemical shifts of all carbons shown in Figure 2 are consistent with the synthesized CPI chemical structure [28,29].

\subsection{Thermal Properties}

The thermal properties of PVA, CPI, and the CPI blend films, synthesized using APS or APS-OH, containing varying amounts ( $\mathrm{wt} \%)$ of PVA, are listed in Table 2 . The glass transition temperature $\left(T_{g}\right)$ of the APS CPI film shows an almost constant value at 204-207 ${ }^{\circ} \mathrm{C}$, regardless of the PVA content $(0-5.0 \mathrm{wt} \%)$. This is the similar to the APS-OH CPI, which exhibited a near-same $T_{g}$ value of $236-240{ }^{\circ} \mathrm{C}$, regardless of the PVA wt $\%$ in the CPI blend. The $T_{g}$ value of the APS-OH CPI blend film was higher than that of the APS CPI, regardless of the PVA wt $\%$. These values show that the -OH group of APS-OH increases 
the $T_{g}$ value of CPI by inducing intermolecular attractions between the CPI main chains through hydrogen bonding. These hydrogen bonds between the CPI main chains interfere with free chain mobility, resulting in an increase in $T_{g}$. Similar papers have been previously published [30]. Figure 3 shows the DSC thermograms of the CPI blend films containing various $\mathrm{PVA} w \mathrm{w} \%$ contents.

Table 2. General properties of CPI blend films with various PVA contents.

\begin{tabular}{|c|c|c|c|c|c|c|c|c|c|c|c|c|}
\hline \multirow{2}{*}{$\begin{array}{c}\text { PVA } \\
(w t \%)\end{array}$} & \multicolumn{6}{|c|}{ APS CPI } & \multicolumn{6}{|c|}{ APS-OH CPI } \\
\hline & $\begin{array}{l}\text { Thickness } \\
\text { ( } \mu \mathrm{m})\end{array}$ & $\begin{array}{c}T_{g} \\
\left({ }^{\circ} \mathrm{C}\right)\end{array}$ & $\begin{array}{l}T_{D}^{i \mathrm{a}} \\
\left({ }^{\circ} \mathrm{C}\right)\end{array}$ & $\begin{array}{c}w t_{R}^{600 \mathrm{~b}} \\
(\%)\end{array}$ & $\begin{array}{c}\text { D.C } \\
(\%)\end{array}$ & 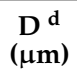 & $\begin{array}{l}\text { Thickness } \\
\text { ( } \mu \mathrm{m})\end{array}$ & $\begin{array}{c}T_{g} \\
\left({ }^{\circ} \mathrm{C}\right)\end{array}$ & $\begin{array}{l}T_{D} \\
\left({ }^{\circ} \mathrm{C}\right)\end{array}$ & $\begin{array}{c}w t_{R} 600 \\
(\%)\end{array}$ & $\begin{array}{l}\text { D.C } \\
(\%)\end{array}$ & $\underset{(\mu \mathrm{m})}{\mathrm{D}}$ \\
\hline 0 (pure CPI) & 24 & 206 & 466 & 52 & 0 & - & 20 & 240 & 335 & 66 & 0 & - \\
\hline 0.5 & 23 & 207 & 468 & 52 & 0 & 0.21 & 21 & 237 & 331 & 67 & 0 & 0.12 \\
\hline 1.0 & 21 & 206 & 463 & 56 & 0 & 0.29 & 24 & 236 & 335 & 67 & 0 & 0.20 \\
\hline 2.0 & 22 & 206 & 465 & 56 & 0 & 0.66 & 22 & 237 & 329 & 65 & 0 & 0.26 \\
\hline 5.0 & 21 & 204 & 465 & 55 & 0 & 0.86 & 22 & 238 & 328 & 67 & 0 & 0.36 \\
\hline 100 (PVA) & - & 44 & 201 & 30 & 18 & - & - & 44 & 201 & 30 & 18 & - \\
\hline
\end{tabular}

${ }^{a}$ Initial $2 \%$ thermal decomposition temperature. ${ }^{b}$ Residual amount $(\%)$ at $600{ }^{\circ} \mathrm{C} .{ }^{c}$ Degree of crystallinity. ${ }^{\mathrm{d}}$ Average pore diameter.

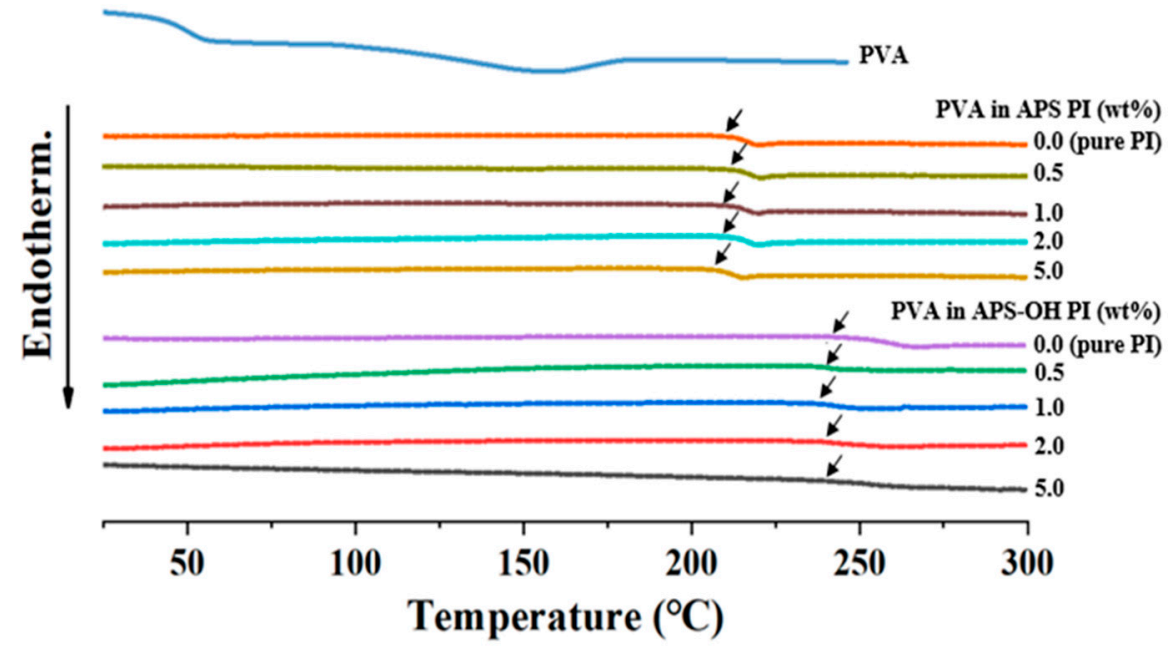

Figure 3. Differential scanning calorimetry (DSC) thermograms of the CPI blend films with various PVA contents.

The initial decomposition temperatures $\left(T_{D}{ }^{i}\right)$ of the CPI blend films containing APS and APS-OH for various amounts of PVA are summarized in Table 2. For the APS CPI, $T_{D}{ }^{i}$ showed a constant value in the range $463-468^{\circ} \mathrm{C}$, although the PVA content increased from 0 to $5.0 \mathrm{wt} \%$ (Table 2). This is similar to the APS-OH CPIs, i.e., as the amount of PVA increased up to $5.0 \mathrm{wt} \%$, the $T_{D}{ }^{i}$ value remained in the range $328-335^{\circ} \mathrm{C}$. Figure 4 shows the TGA values of CPI films synthesized using monomers with two different structures. In the thermograms of the two CPI series according to the various amounts of PVA, the transition temperatures $\left(T_{g}, T_{m}\right.$, and $\left.T_{D}{ }^{i}\right)$ of PVA were not observed. These results imply that the water-soluble PVA in water was completely removed from the CPI blend film.

The residual amount (\%) of the two CPI films at $600{ }^{\circ} \mathrm{C}\left(\mathrm{wt}_{\mathrm{R}}{ }^{600}\right)$ showed an almost constant value as the PVA $\mathrm{wt} \%$ increased to $5.0 \mathrm{wt} \%$, i.e., the $w t_{R}{ }^{600}$ values of the APS CPI and APS-OH PI films were maintained at $52-56 \%$ and $65-67 \%$, respectively. Because the thermal stability of the -OH group was low; therefore, the $T_{D}{ }^{i}$ value of APS-OH PI was lower than that of APS PI. On the contrary, due to the intermolecular hydrogen bonding of the PI main chain by the -OH groups, the $w t_{R}{ }^{600}$ of APS-OH CPI was higher than that of APS CPI. The $T_{g}, T_{D}{ }^{i}$, and $w t_{R}{ }^{600}$ values suggest that the PVA content had little effect on the thermal properties because the water-soluble PVA present in the PI film was removed by immersion in water. 

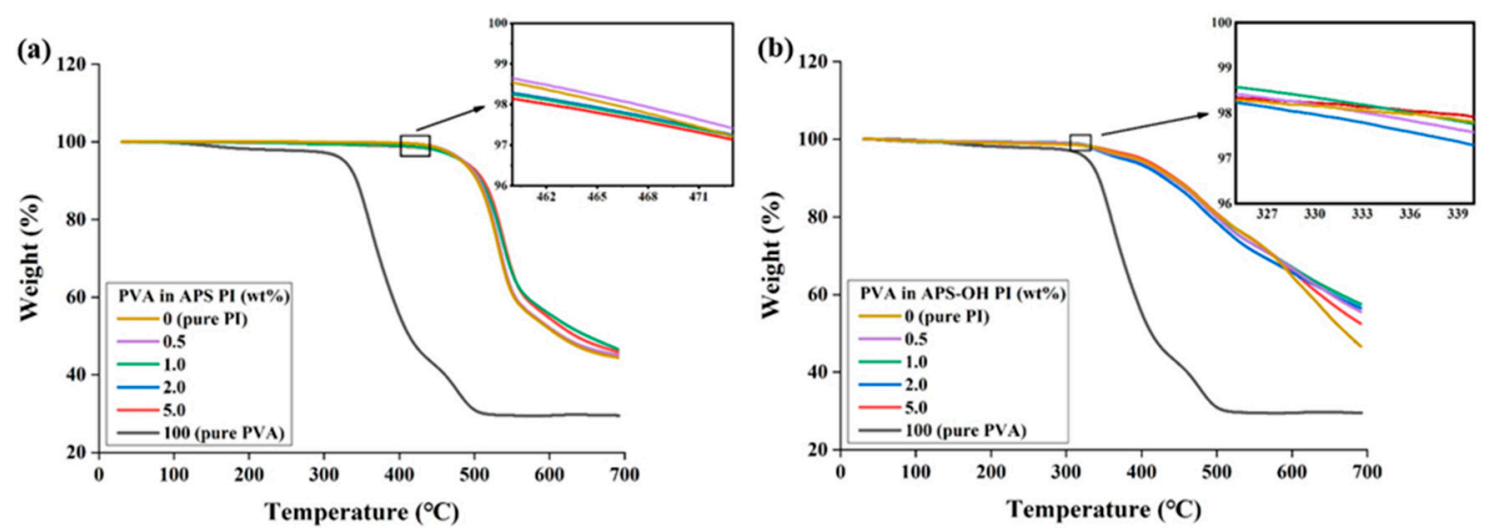

Figure 4. Thermogravimetric analysis (TGA) thermograms of the CPI blend films with various PVA contents: (a) APS CPI and (b) APS-OH CPI.

In the TGA thermogram of Figure $4 \mathrm{~b}$, two-stage pyrolysis was observed at $\sim 320{ }^{\circ} \mathrm{C}$ and $\sim 420{ }^{\circ} \mathrm{C}$, respectively. When - $\mathrm{OH}$ group is present in the polymer structure, $\mathrm{PI}$ is converted to polybenzoxazole ( $\mathrm{PBO}$ ), which has superior thermal stability through thermal rearrangement (TR) during heat treatment [31,32]. In many studies, $\mathrm{PBO}$ films processed by TR show abnormal microporous properties in the solid phase due to a large increase in free volume during TR. The PBO film obtained by heat treatment of APS-OH PI is an excellent material for gas separation applications, such as $\mathrm{CO}_{2} / \mathrm{CH}_{4}$ and $\mathrm{CO}_{2} / \mathrm{N}_{2}[33,34]$.

\subsection{Membrane Morphology}

The XRD diffractograms of two types of CPI blend films containing varying amounts of PVA are shown in Figure 5. Peaks characteristic for PVA are generally observed at $2 \theta=19.68^{\circ}(\mathrm{d}=4.51 \AA)$ and $23.64^{\circ}(\mathrm{d}=3.75 \AA)$. However, even if the amount of PVA increased from 0 to $5.0 \mathrm{wt} \%$ in all peaks of the APS and APS-OH CPI blends, no intrinsic peak of PVA was observed. In addition, the degree of crystallinity was almost constant, regardless of the amount of PVA contained in the CPI blend film (Table 2). These XRD patterns show that the PVA components present in the CPI blend film were completely removed at all PVA concentrations. The results of XRD are approximate results showing the dispersion of the filler and cross-checking with electron microscopy is required to fully confirm a particular dispersion state.

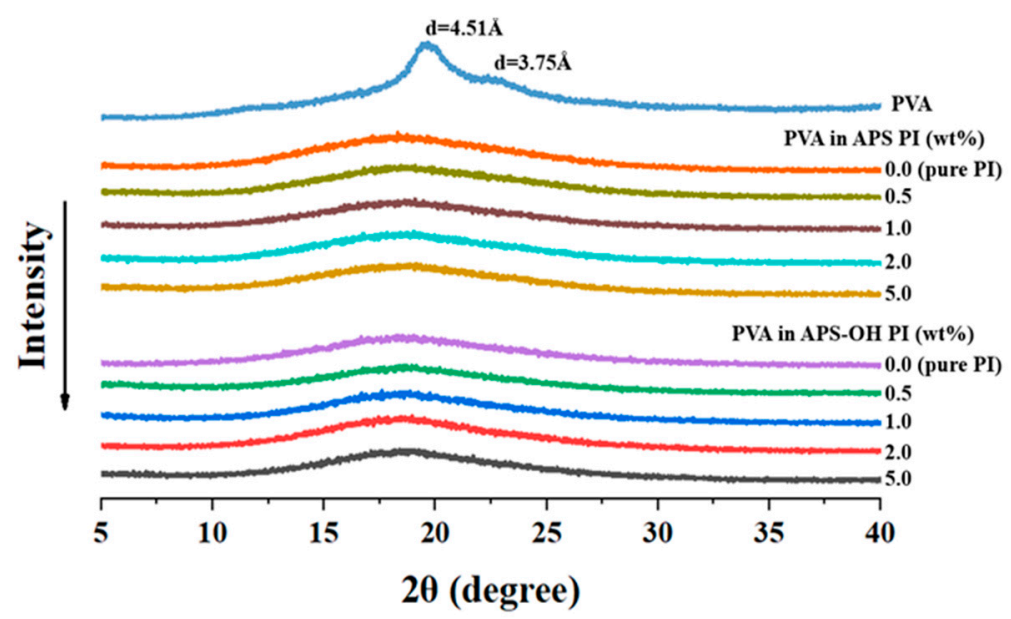

Figure 5. X-ray diffractometer (XRD) diffractograms of the CPI blend films with various PVA contents.

SEM was used to confirm the various pore dispersions in the CPI microporous films after PVA removal. Figure 6 represents the SEM micrographs of the porous APS CPI films at various amounts of PVA. The pore size gradually increased according to the PVA 
concentration increased to $5.0 \mathrm{wt} \%$, i.e., when the PVA concentration increased to $0.5 \mathrm{wt} \%$, the average pore diameter was $0.21 \mu \mathrm{m}$, but, when the PVA wt $\%$ became 2.0, the pore diameter was $\sim 0.66 \mu \mathrm{m}$. When the PVA concentration was $5.0 \mathrm{wt} \%$, the average pore size increased to an average of $0.86 \mu \mathrm{m}$ (see Table 2). Most of the pores shown in Figure 6 were evenly observed throughout the CPI film.

(a)

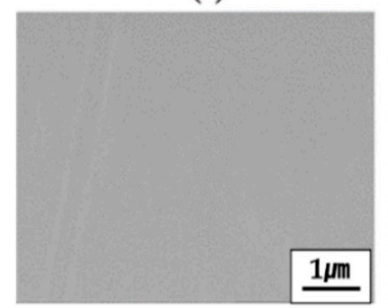

(b)

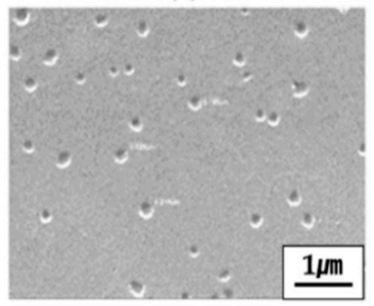

(c)

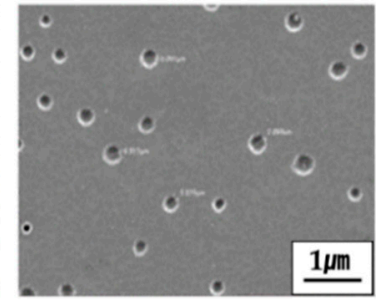

(e)
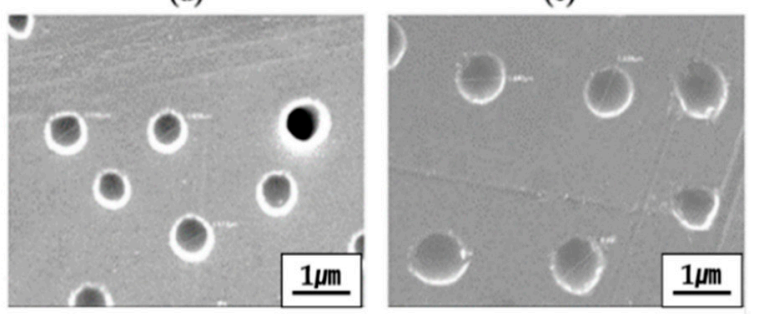

Figure 6. Scanning electron microscope (SEM) micrographs of the micro-pores in the APS CPI blend films with (a) 0, (b) 0.5, (c) 1.0, (d) 2.0, and (e) $5.0 \mathrm{wt} \%$ PVA.

Figure 6 also shows the average size of the micropores according to the PVA concentration in the CPI blend film. When the PVA content increased up to $5.0 \mathrm{wt} \%$ in the CPI blend film, the PVA self-aggregates and the size of the particles increased constantly. When these PVA particles were dissolved and removed by water, the pore size of the CPI blend film increased accordingly. Table 2 shows the average size of the membrane pores according to the PVA concentration in the CPI blend film.

Similar results were observed for the APS-OH CPI, as listed in Table 2. The average pore diameter gradually increased as the amount of PVA increased up to $5.0 \mathrm{wt} \%$ in this CPI blend, e.g., when the PVA wt \% increased from 0 to 1.0 in the CPI blend, the average pore diameter was observed to be $0.20 \mu \mathrm{m}$. However, when the PVA increased to $5.0 \mathrm{wt} \%$, the pore diameter also increased with an average of $0.36 \mu \mathrm{m}$. Figure 7 shows the change in pore size according to the PVA concentration in the APS-OH CPI microporous film.

The constant pore size of the CPI microporous film could be easily obtained by controlling the amount of PVA contained in the blend film. This result was possible not only with hydrophilic APS-OH monomer but also with non-hydrophilic APS monomer. The separation technique used to treat suspensions usually uses a microfiltration method, mainly filters with a porous membrane size of 0.01 to $1.0 \mu \mathrm{ms}$. Therefore, the porous CPI film obtained in this study can filter out large portions of suspended particles, clays, bacteria or large viruses present in solution $[35,36]$.

To compare the overall pore dispersion, SEM images of micro-pores in two CPI blend films containing the same amount of PVA are shown in Figure 8. After blending $5 \mathrm{wt} \%$ PVA with CPI, the average pore diameters of APS and APS-OH CPI microporous films with the PVA components removed by water were found to be approximately $0.84-0.88 \mu \mathrm{m}$ and $0.34-0.38 \mu \mathrm{m}$, respectively. The overall pore size was constant and the dispersibility excellent. The average pore diameter of the APS-OH CPI film was smaller than that of the APS CPI film at the same PVA content. This is because a dense structure is formed by the main chains of CPI due to the hydrogen bonding of the -OH groups in APS-OH CPI. Therefore, when PVA is dissolved and eliminated from the PI blend film, the pore size of the APS-OH CPI film is smaller than that of the APS CPI film. 
(a)

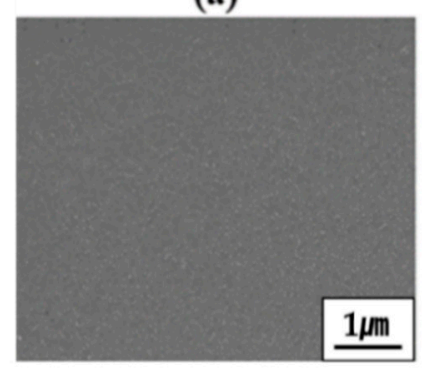

(b)

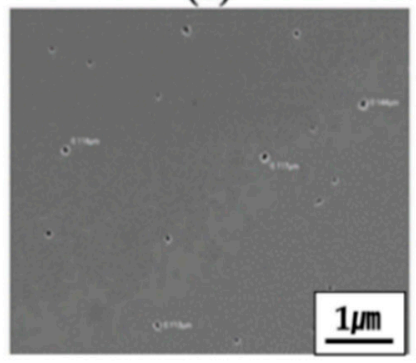

(c)

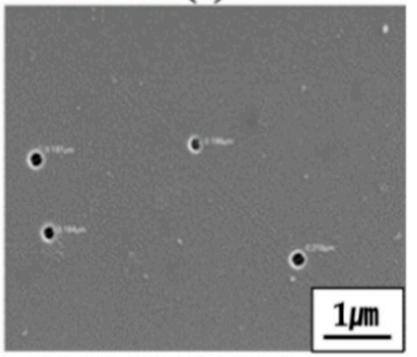

(d)

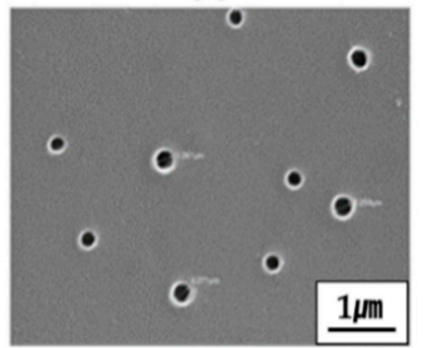

(e)

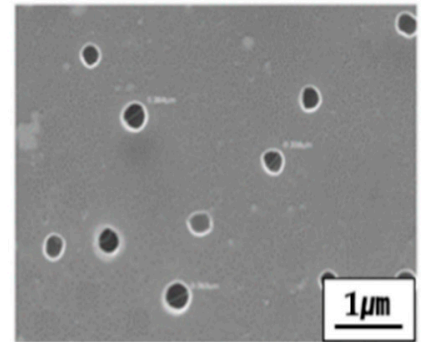

Figure 7. SEM micrographs of the micro-pores in the APS-OH CPI blend films with (a) 0, (b) 0.5, (c) 1.0, (d) 2.0, and (e) 5.0 wt $\%$ PVA.

(a)

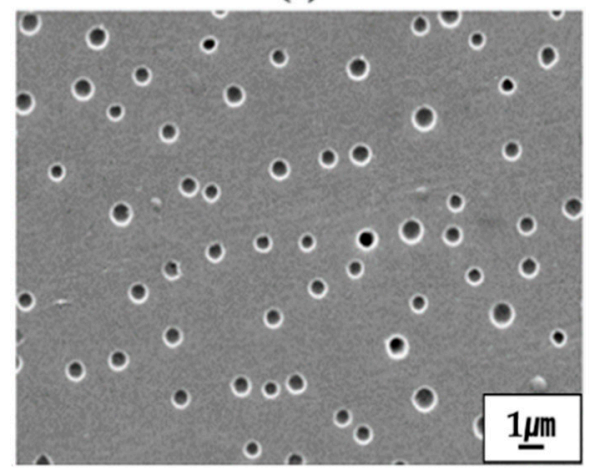

(b)

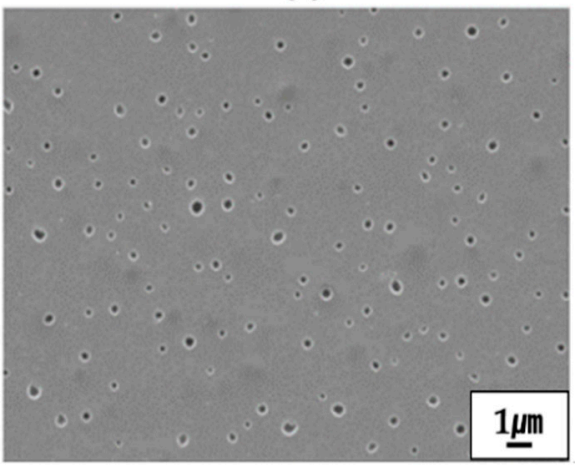

Figure 8. Low-magnification $(\times 5000)$ SEM micrographs of the CPI microporous films containing (a) APS and (b) APS-OH with $5.0 \mathrm{wt} \%$ PVA.

\subsection{Optical Transparency}

The optical transparencies of the CPI blend film can be determined by the yellow index (YI), cutoff wavelength $\left(\lambda_{\circ}\right)$, and transmittance at $500 \mathrm{~nm}$ wavelength (500 $\left.{ }^{\text {trans }} \mathrm{nm}\right)$ [37-39]. The results obtained using UV-vis spectroscopy are displayed in Table 3 and Figure 9, respectively. For all APS and APS-OH PI blend films, regardless of the amount of PVA $\mathrm{wt} \%$, the $\lambda_{\mathrm{o}}$ value representing the initial transmittance was less than $400 \mathrm{~nm}$, before the visible light region (see Table 3). These $\lambda_{\mathrm{o}}$ values are considerably lower compared to commercially available Kapton ${ }^{\circledR}$ PI films, indicating the almost-transparent properties of these films. As shown in Table 3, the APS CPI blend film showed a maximum UV transmittance of $81-88 \%$ at $500 \mathrm{~nm}$ depending on the change in the content of PVA. In addition, the resulting value of the APS-OH CPI blend film significantly decreased from 83 to $18 \%$ as the amount of PVA increased to $5 \mathrm{wt} \%$. The UV transmittance decreased as the content of PVA increased because the -OH groups in the PI main chain increased the bonding strength between the CPI chains due to intermolecular hydrogen bonding, resulting in the formation of dense structures. 
Table 3. Optical transparencies of the CPI blend films containing various PVA contents.

\begin{tabular}{|c|c|c|c|c|c|c|}
\hline \multirow{2}{*}{$\begin{array}{c}\text { PVA } \\
(w t \%)\end{array}$} & \multicolumn{3}{|c|}{ APS CPI } & \multicolumn{3}{|c|}{ APS-OH CPI } \\
\hline & $\begin{array}{l}\lambda_{0}{ }^{a} \\
(\mathrm{~nm})\end{array}$ & $\begin{array}{c}500 \mathrm{~nm}^{\text {trans }} \\
(\%)\end{array}$ & $\mathbf{Y I}^{\mathbf{b}}$ & $\begin{array}{c}\lambda_{0} \\
(\mathrm{~nm})\end{array}$ & $\begin{array}{c}500 \mathrm{~nm}^{\text {trans }} \\
(\%)\end{array}$ & YI \\
\hline 0 (pure CPI) & 390 & 88 & 2 & 370 & 83 & 5 \\
\hline 0.5 & 385 & 84 & 2 & 370 & 81 & 6 \\
\hline 1.0 & 370 & 81 & 2 & 380 & 74 & 7 \\
\hline 2.0 & 380 & 87 & 3 & 390 & 56 & 9 \\
\hline 5.0 & 375 & 82 & 2 & 390 & 18 & 10 \\
\hline
\end{tabular}

${ }^{\mathrm{a}}$ Cut-off wavelength. ${ }^{\mathrm{b}}$ Yellow index.

(a)

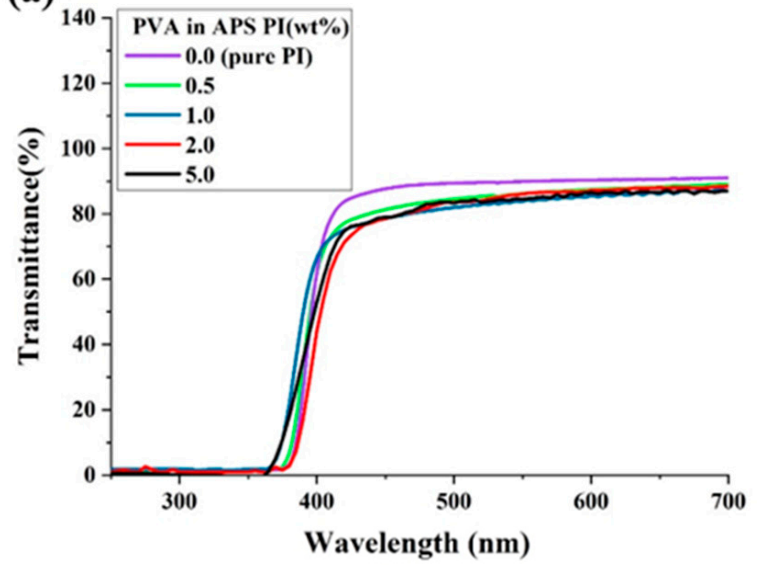

(b)

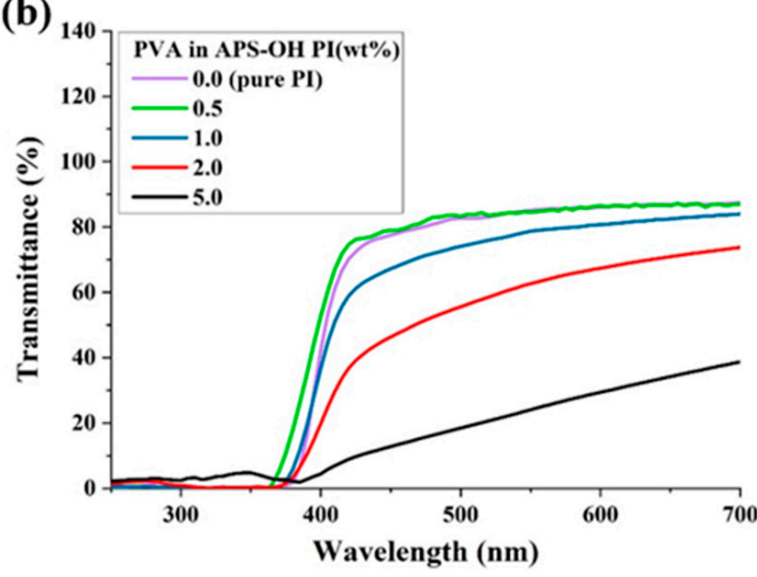

Figure 9. UV-visible (UV-vis.) transmittance of the CPI blend films containing (a) APS and (b) APS-OH with various PVA contents.

Table 3 lists the YI values of the APS CPI and APS-OH CPI blend films. The YI values of the APS CPI blend film were constant, regardless of all PVA content $(0.5-5.0 \mathrm{wt} \%)$, and were very low overall $(\mathrm{YI}=2-3)$. This value can be obtained from an almost colorless, transparent film, e.g., poly(methyl methacrylate) (PMMA) shows YI = 1-2 [40]. Conversely, for the APS-OH CPI blend film, the YI value steadily increased from 5 to 10 as the amount of PVA increased from 0 to $5 \mathrm{wt} \%$. The reason is also the hydrogen bonding between the polymer chains. In order to confirm the actual colorless transparency, a 20-24- $\mu \mathrm{m}$-thick film was prepared and tested with the naked eye. APS CPI showed very good optical transparency at all concentrations (Figure 10), but, for the APS-OH CPI film, when the PVA content increased up to $5 \mathrm{wt} \%$, the yellow intensity further increased (Figure 11). However, both series of CPI films resulted in no difficulty reading logos through the film.

\subsection{Solubility}

The synthesized CPI blend films were examined for solubility in several solvents and the results are listed in Table 4. None of the films dissolved in the general-purpose solvents acetone, chloroform, alcohol, or toluene, and did not dissolve in DMAc, $\mathrm{N}$-methyl2-pyrrolidone (NMP), or dimethyl sulfoxide (DMSO), often used as solvents for PI.

Because CPI is a highly functional polymer material with very strong chemical and heat resistance, its use is sometimes restricted to that of a general engineering material. However, the CPI blend film obtained in this study can be applied to the field of membranes using harsh, strong solvents, and the colorless, transparent membrane is another advantage. 
(a)

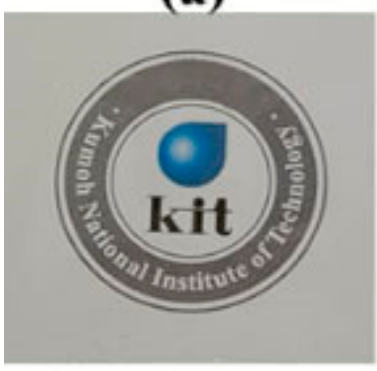

(b)

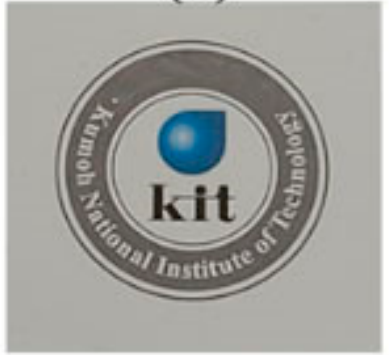

(c)

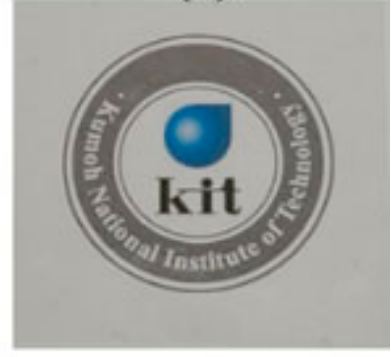

(e)

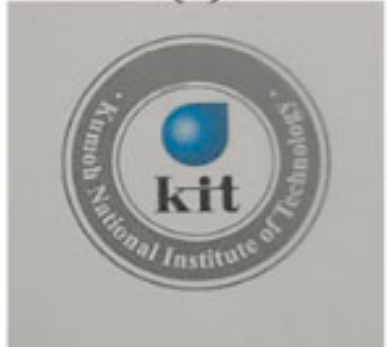

Figure 10. Photographs of the APS CPI blend films containing (a) 0, (b) 0.5, (c) 1.0, (d) 2.0, and (e) $5.0 \mathrm{wt} \%$ PVA.

(a)

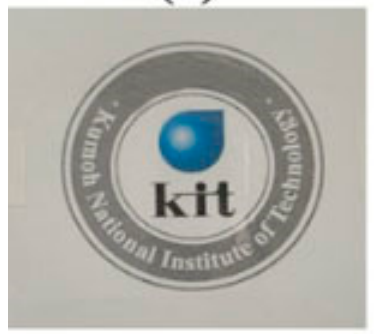

(b)

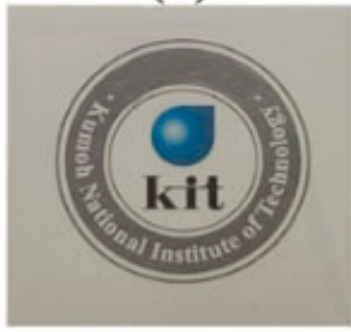

(c)

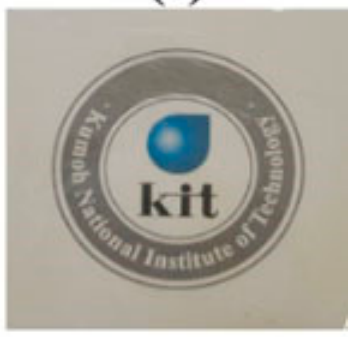

(d)

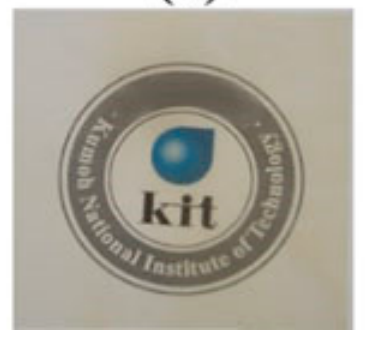

(e)

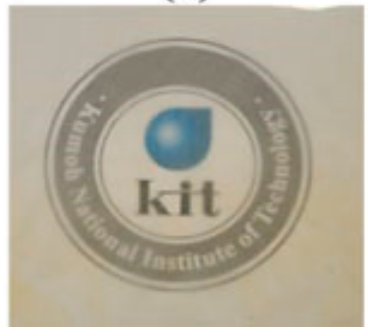

Figure 11. Photographs of the APS-OH CPI blend films containing (a) 0 , (b) 0.5, (c) 1.0 , (d) 2.0 , and (e) $5.0 \mathrm{wt} \%$ PVA.

Table 4. Solubility of the CPI blend films.

\begin{tabular}{cccccccccccc}
\hline CPI & Act & $\mathrm{CHCl}_{3}$ & $\mathrm{CH}_{2} \mathrm{Cl}_{2}$ & DMAc & DMF & DMSO & $\mathrm{CH}_{3} \mathrm{OH}$ & NMP & Tol & THF & Py \\
\hline APS & $\times$ & $\times$ & $\times$ & $\times$ & $\times$ & $\times$ & $\times$ & $\times$ & $\times$ & $\times$ & $\times$ \\
APS-OH & $\times$ & $\times$ & $\times$ & $\times$ & $\times$ & $\times$ & $\times$ & $\times$ & $\times$ & $\times$ & $\times$ \\
\hline
\end{tabular}

$\times$ : Very poor. Act: Acetone, DMAc: N,N-dimethylacetamide, DMF: $N, N$-dimethylformamide, DMSO: dimethyl sulfoxide, NMP: $N$-methyl2-pyrrolidone, Tol: Toluene, THF: tetrahydrofuran, Py: Pyridine. 


\section{Conclusions}

PAA was synthesized by reacting two types of diamines, APS or APS-OH, with anhydrous BPADA. PAA was blended with various PVA concentrations and subjected to various heat treatment processes to produce CPI/PVA blend films. These films were immersed in water to remove water-soluble PVA to prepare two series of microporous $\mathrm{CPI}$ films. Because the APS-OH monomer used as an amine contains an - $\mathrm{OH}$ group in the PI main chain, the structure enabled hydrogen bonding between PI and PVA present in the blend, as well as between PI chains. The properties were compared with those of APS CPI without hydrogen bonds. Particularly in the case of APS-OH CPI, the pore size can be easily adjusted owing to its hydrophilicity. Therefore, APS-OH CPI can be used in MF membranes that require optical transparency and high functionality.

The CPI microporous film developed in this study should be useful, not only as a filtration field but also as a functional polymer material because of its superior thermal properties, optical transparency, and solvent resistance compared to general engineering polymers.

Author Contributions: J.-H.C. decided on the polymer structure and experimental method of the research theme, and wrote the manuscript using the research results. J.W.K., S.J.L., M.Y.C. synthesized the polymers and analyzed their characteristics. All authors reviewed the manuscript together. All authors have read and agreed to the published version of the manuscript.

Funding: This research was supported by the Basic Science Research Program through the National Research Foundation of Korea (NRF), funded by the Ministry of Education (2016R1A6A1A03012069 and 2018R1D1A1B07045502).

Institutional Review Board Statement: Not applicable.

Informed Consent Statement: Not applicable.

Data Availability Statement: The data presented in this study are available on request from the corresponding author.

Conflicts of Interest: The authors declare no conflict of interest.

\section{References}

1. Kuang, Y.; Zhang, X.; Zhou, S. Adsorption of Methylene Blue in Water onto Activated Carbon by Surfactant Modification. Water 2020, 12, 587. [CrossRef]

2. Kalla, S. Use of Membrane Distillation for Oily Wastewater Treatment-A Review. J. Environ. Chem. Eng. 2021, 9, 104641. [CrossRef]

3. Chi, X.Y.; Zhang, P.Y.; Guo, X.J.; Xu, Z.L. A Novel TFC Forward Osmosis (FO) Membrane Supported by Polyimide (PI) Microporous Nanofiber Membrane. Appl. Surf. Sci. 2018, 427, 1-9. [CrossRef]

4. Anis, S.; Hashaikeh, R.; Hilal, N. Microfiltration Membrane Processes: A Review of Research Trends Over the Past Decade. J. Water Process. Eng. 2019, 32, 100941. [CrossRef]

5. Mohammad, A.; Teow, Y.; Ang, W.; Chung, Y.; Oatley-Radcliffe, D.; Hilal, N. Nanofiltration Membranes Review: Recent Advances and Future Prospects. Desalination 2015, 356, 226-254. [CrossRef]

6. Charcosset, C. Ultrafiltration, Microfiltration, Nanofiltration and Reverse Osmosis in Integrated Membrane Processes. In Integrated Membrane Systems and Processes; Wiley: Hoboken, NJ, USA, 2016; pp. 1-22.

7. Dolar, D.; Košutić, K. Removal of Pharmaceuticals by Ultrafiltration (UF), Nanofiltration (NF), and Reverse Osmosis (RO). In Comprehensive Analytical Chemistry; Elsevier: Amsterdam, The Netherlands, 2013; Volume 62, pp. 319-344.

8. Belfort, G.; Davis, R.H.; Zydney, A.L. The Behavior of Suspensions and Macromolecular Solutions in Crossflow Microfiltration. J. Membr. Sci. 1994, 96, 1-58. [CrossRef]

9. Zsigmondy, R. Filter and method of producing same. U.S. Patent US1421341A, 27 June 1922.

10. Zhong, J.; Sun, X.; Wang, C. Treatment of Oily Wastewater Produced from Refinery Processes Using Flocculation and Ceramic Membrane Filtration. Sep. Purif. Technol. 2003, 32, 93-98. [CrossRef]

11. Das, B.; Chakrabarty, B.; Barkakati, P. Preparation and Characterization of Novel Ceramic Membranes for Micro-Filtration Applications. Ceram. Int. 2016, 42, 14326-14333. [CrossRef]

12. Howe, K.J.; Clark, M.M. Fouling of Microfiltration and Ultrafiltration Membranes by Natural Waters. Environ. Sci. Technol. 2002, 36, 3571-3576. [CrossRef] [PubMed]

13. Grosso, V.; Vuono, D.; Bahattab, M.A.; Di Profio, G.; Curcio, E.; Al-Jilil, S.A.; Alsubaie, F.; Alfife, M.; Nagy, J.B.; Drioli, E.; et al. Polymeric and Mixed Matrix Polyimide Membranes. Sep. Purif. Technol. 2014, 132, 684-696. [CrossRef] 
14. Ba, C.; Economy, J. Preparation of PMDA/ODA Polyimide Membrane for Use as Substrate in a Thermally Stable Composite Reverse Osmosis Membrane. J. Membr. Sci. 2010, 363, 140-148. [CrossRef]

15. Ni, H.-J.; Liu, J.-G.; Wang, Z.-H.; Yang, S.-Y. A Review on Colorless and Optically Transparent Polyimide Films: Chemistry, Process and Engineering Applications. J. Ind. Eng. Chem. 2015, 28, 16-27. [CrossRef]

16. Liaw, D.-J.; Wang, K.-L.; Huang, Y.-C.; Lee, K.-R.; Lai, J.-Y.; Ha, C.-S. Advanced Polyimide Materials: Syntheses, Physical Properties and Applications. Prog. Polym. Sci. 2012, 37, 907-974. [CrossRef]

17. Gaaz, T.S.; Sulong, A.B.; Akhtar, M.N.; Kadhum, A.A.H.; Mohamad, A.B.; Al-Amiery, A.A. Properties and Applications of Polyvinyl Alcohol, Halloysite Nanotubes and Their Nanocomposites. Molecules 2015, 20, 22833-22847. [CrossRef]

18. Aslam, M.; Kalyar, M.A.; Raza, Z.A. Polyvinyl Alcohol: A Review of Research Status and Use of Polyvinyl Alcohol Based Nanocomposites. Polym. Eng. Sci. 2018, 58, 2119-2132. [CrossRef]

19. Boussemghoune, M.; Chikhi, M.; Balaska, F.; Ozay, Y.; Dizge, N.; Kebabi, B. Preparation of a Zirconia-Based Ceramic Mem-brane and Its Application for Drinking Water Treatment. Symmetry 2020, 12, 933. [CrossRef]

20. Peng, F.; Huang, X.; Jawor, A.; Hoek, E.M.V. Transport, Structural, and Interfacial Properties of Poly (Vinyl Alcohol)-Polysulfone Composite Nanofiltration Membranes. J. Membr. Sci. 2010, 353, 169-176. [CrossRef]

21. Zhang, H.; Tung, W.Y.; Li, X.; Jin, H.; Deng, R.; Chen, Y.M.; Mao, Y.; Zhu, Y. Conjugated Polymer with Dynamic and Thermoreversible Hydrogen Bonding on the Backbone. Polymer 2020, 203, 122787. [CrossRef]

22. Qiu, F.-X.; Zhou, Y.-M.; Liu, J.-Z. The Synthesis and Characteristic Study of 6FDA-6FHP-NLO Polyimide/SiO 2 Nanohybrid Materials. Eur. Polym. J. 2004, 40, 713-720. [CrossRef]

23. Shin, H.I.; Chang, J.-H. Transparent Polyimide/Organoclay Nanocomposite Films Containing Different Diamine Monomers. Polymers 2020, 12, 135. [CrossRef] [PubMed]

24. Pavia, D.L.; Lampman, G.M.; Kriz, G.S.; Vyvyan, J.A. Introduction to Spectroscopy; Cengage Learning: Boston, MA, USA, 2008; Volume 2, pp. 15-104.

25. Rusu, R.-D.; Constantin, C.-P.; Drobota, M.; Gradinaru, L.-M.; Butnaru, M.; Pislaru, M. Polyimide Films Tailored by UV Irra-diation: Surface Evaluation and Structure-Properties Relationship. Polym. Degrad. Stab. 2020, 177, 109182. [CrossRef]

26. Fukukawa, K.-I.; Okazaki, M.; Sakata, Y.; Urakami, T.; Yamashita, W.; Tamai, S. Synthesis and Properties of Multi-Block Semi-alicyclic Polyimides for Thermally Stable Transparent and Low CTE Film. Polymer 2013, 54, 1053-1063. [CrossRef]

27. Zhai, L.; Yang, S.; Fan, L. Preparation and Characterization of Highly Transparent and Colorless Semi-Aromatic Polyimide Films Derived from Alicyclic Dianhydride and Aromatic Diamines. Polymer 2012, 53, 3529-3539. [CrossRef]

28. Kim, S.D.; Lee, S.; Heo, J.; Kim, S.Y.; Chung, I.S. Soluble Polyimides with Trifluoromethyl Pendent Groups. Polymer 2013, 54, 5648-5654. [CrossRef]

29. Pouchert, C.; Behnke, J. The Aldrich Library of 13C and 1 H FT NMR spectra; Aldrich Chem. Co., Inc.: Milwaukee, WI, USA, 1993.

30. Kim, J.W.; Chang, J.-H. Syntheses of Colorless and Transparent Polyimide Membranes for Microfiltration. Polymers 2020, 12, 1610. [CrossRef]

31. Sanders, D.F.; Guo, R.; Smith, Z.P.; Liu, Q.; Stevens, K.A.; McGrath, J.E.; Paul, D.R.; Freeman, B.D. Influence of Polyimide Precursor Synthesis Route and Ortho-Position Functional Group on Thermally Rearranged (TR) Polymer Properties: Conversion and Free Volume. Polymer 2014, 55, 1636-1647. [CrossRef]

32. Scholes, C.A.; Ribeiro, C.P.; Kentish, S.E.; Freeman, B.D. Thermal Rearranged Poly (benzoxazole)/Polyimide Blended Mem-branes for $\mathrm{CO}_{2}$ Separation. Sep. Purif. Technol. 2014, 124, 134-140. [CrossRef]

33. Comer, A.C.; Ribeiro, C.P.; Freeman, B.D.; Kalakkunnath, S.; Kalika, D.S. Dynamic Relaxation Characteristics of Thermally Rearranged Aromatic Polyimides. Polymer 2013, 54, 891-900. [CrossRef]

34. Wang, H.; Paul, D.R.; Chung, T.-S. The Effect of Purge Environment on Thermal Rearrangement of Ortho-Functional Poly-amide and Polyimide. Polymer 2013, 54, 2324-2334. [CrossRef]

35. MaryTheresa, M.P.; Eric, M.V.H. A Review of Water Treatment Membrane Nanotechnologies. Energy Environ. Sci. 2011, 4, 1946-1971.

36. Schäfer, A.; Schwicker, U.; Fischer, M.M.; Fane, A.G.; Waite, T.D. Microfiltration of Colloids and Natural Organic Matter. J. Membr. Sci. 2000, 171, 151-172. [CrossRef]

37. Kudo, H.; Sudo, S.; Oka, T.; Hama, Y.; Oshima, A.; Washio, M.; Murakami, T. Ion-Beam Irradiation Effects on Polyimide-UV-vis and Infrared Spectroscopic Study. Radiat. Phys. Chem. 2009, 78, 1067-1070. [CrossRef]

38. Jang, Y.M.; Seo, J.Y.; Chae, K.H.; Yi, M.H. Positive-Type Photosensitive Polyimide Based on a Photobase Generator Containing oxime-Urethane Groups as a Photosensitive Compound. Macromol. Res. 2006, 14, 300-305. [CrossRef]

39. Shin, H.I.; Kwark, Y.-J.; Chang, J.-H. Colorless and Transparent Copolyimides and Their Nanocomposites: Thermo-Optical Properties, Morphologies, and Gas Permeabilities. Polymers 2019, 11, 585. [CrossRef] [PubMed]

40. Yang, C.-P.; Su, Y.-Y. Colorless and High Organosoluble Polyimides from 2, 5-bis(3,4-Dicarboxy-Phenoxy)-t-Butylbenzene Di-Anhydride and Aromatic Bis(Ether Amine)s Bearing Pendent Trifluoromethyl Groups. Polymer 2005, 46, 5778-5788. [CrossRef] 